\title{
"O ENVIR DE ESPACOS": CARTOGRAFIA E GEOESTRATÉGIA NO ROMANCE BRASILEIRO DO SÉCULO XX
}

\author{
Érico Melo \\ Universidade de São Paulo
}

Resumo

Se, como propõe Dominique Maingueneau, o romance pode ser considerado um macroato de fala ficcional, o mapeamento das posições das vozes narrativas e pontos de vista no espaço reconstruído pela narrativa adquire importância especial para a análise geocrítica. Este artigo analisa alguns regimes geoestratégicos do romance brasileiro no quadro histórico da conquista territorial do sertão pelas cidades no século $\mathrm{XX}$, com destaque para a participação da cartografia no repertório espacial de romancistas selecionados.

\section{Abstract}

If the novel as literary genre can be understood as a macro-act of fictional speech, as proposed by Dominique Maingueneau, the task of mapping narrative voices, points of view, and their positions in the narrative space attains capital importance for geocriticism. This article investigates the spatiality of a small selection of novels in order to outline their geostrategic regimes in the historic context of the territorial conquest of the sertão by the cities.

\author{
Palavras-chave \\ Romance \\ brasileiro, \\ século XX, \\ geografia, \\ espaço, \\ contexto e \\ enunciação \\ literária
}

\section{Keywords}

Brazilian novel, 20th Century, Geography, space, context and literary enunciation 
Antes de mais nada, como recomenda Franco Moretti, deve-se insistir em que "a geografia não é um recipiente inerte, não é uma caixa onde a história cultural 'ocorre', mas uma força ativa, que impregna o campo literário e o conforma em profundidade".3 Não se pretende aqui sugerir um modelo de interação determinístico, linear ou de mão única entre os espaços engendrados pelo romance brasileiro e os contextos histórico-geográficos de seus regimes de enunciação. Essa relação antes se dá como um multívoco jogo dialógico que a crítica precisa avaliar in vivo se pretende elucidar as artimanhas espaçotemporais do discurso narrativo. $\mathrm{O}$ estudo da geografia do romance deve ter liberdade de movimentos suficiente para se aproximar e se afastar à vontade do texto; alterar os ângulos de ataque e reflexão segundo a configuração cambiante do mundo reconstruído, tornando visíveis as convoluções e fraturas; os limites exteriores e as vias de comunicação interna; os perfis de estase e transiência das vozes e pontos de vista. Olho de pássaro e ouvido de mateiro.

O objetivo deste artigo é propor um roteiro de ação para compreender o tratamento dado pela ficção longa às profundas transformações do território brasileiro na esteira da urbanização e da industrialização. Como o romance do século XX gerencia suas relações com o contexto geográfico? Parafraseando Guimarães Rosa, como operam os romancistas ao captar e responder os "recados" da geografia?

Uma comparação entre escritores selecionados do cânone novecentista aponta para distintos modos de ocupação ficcional do espaço-nação durante a fase crítica do embate territorial entre o sertão e as cidades. Essa comparação percorre uma pequena galeria de romances de ponta, dentro da qual se estabelecem relações de semelhança e antagonismo segundo as flutuações da linha de frente entre os dois polos espaciais ao longo do século passado. Esaú e Jacó (1904), Serafim Ponte Grande (1931) e O encontro marcado (1956), apesar de suas evidentes dissimilaridades, se conectam com a mesma intensidade visceral ao crescimento acelerado das grandes cidades. Encenados no polo oposto, São Bernardo (1934), Grande sertão: veredas (1956) e A pedra do reino (1971) são títulos "sertanejos" igualmente dissonantes entre si, mas que compartilham os temas da conquista territorial do sertão e da redefinição de suas fronteiras pelo capital e pelo Estado.

Ah, tempo de jagunço tinha mesmo de acabar, cidade acaba com o sertão. Acaba? ${ }^{4}$

Ao longo de quase todo o período colonial, a ocupação econômica e populacional do Brasil se aferrou à faixa litorânea delimitada pelas serras e tabuleiros que assinalavam os confins do mundo conhecido para o colonizador português - bem ao contrário dos domínios espanhóis na América, desde cedo baseados na exploração mineradora dos altiplanos do interior continental. Numa sentença célebre, o frei Vicente do Salvador constatou que os 
primeiros colonos do Brasil preferiam "andar arranhando ao longo do mar como caranguejos" 5 a conquistar os sertões de floresta, cerrado e caatinga do vasto interior. No litoral açucareiro das capitanias do Nordeste, em meados do século XVII a faixa de colonização não ultrapassava 70-80 km de largura, ${ }^{6}$ mesma medida da presente fronteira convencional entre a zona da mata e o agreste, o que indica sua durabilidade no imaginário territorial do país. Os engenhos e localidades pernambucanos citados em $A$ pedra do reino, rodeados de lembranças dos feitos épicos das guerras holandesas, se situam nessa estreita região da zona da mata, assim como a fazenda São Bernardo de Graciliano Ramos, já nos confins do sertão alagoano.

Nas donatarias meridionais, sitiadas por escarpados paredões rochosos, o alcance da colonização mal cobria a mesma distância. Poucos mapas do Brasil avançavam além do desenho da costa e da situação dos portos, e quando o faziam precisavam recorrer à imaginação e à lenda. Além das habituais referências a tribos canibais e à natureza exótica, nas cartas que mostram o interior da colônia quase sempre aparecem lagos, montanhas, rios e outros acidentes geográficos que só se explicam pela fantasia delirante dos exploradores, ou por erros grosseiros na tradução dos relatos de nativos. Por exemplo, o São Francisco e o Real (curso d'água muito mais curto e menos caudaloso que o Velho Chico) durante muito tempo foram desenhados como rios gêmeos, emanados de um mesmo lago central e que se cruzavam (!) em diversos pontos. Nas primeiras décadas do século XVIII, os rumos dos maiores rios do Brasil e as divisões orográficas entre suas bacias ainda não haviam sido elucidados pela cartografia europeia. ${ }^{7}$

Até o limiar do século XX, o jovem país se constituiu na prática de um arquipélago de províncias litorâneas integradas por esparsas rotas de cabotagem, e que ainda começava a explorar os "vazios" de seus sertões continentais. No entanto, desde o século XVIII o conhecimento dos roteiros bandeirantes até os distritos mineradores - espécies de mapas rudimentares com indicações "narrativas" do trajeto - havia se tornado um ativo estratégico para a Coroa portuguesa, que estimulou novos e mais acurados mapeamentos do interior. Simultaneamente ao surgimento das vilas e cidades da mineração nos sertões de Minas Gerais, Mato Grosso e Goiás, criadores de gado e todos os tipos de boiadeiros, tropeiros e lavradores avançaram pelas chapadas e veredas para alargar o território desbravado, na esteira das necessidades logísticas da economia do ouro. Mas, grosso modo, o futuro Império se constituiu desde sua fundação colonial num frouxo conjunto de "ilhas" socioculturais com escassa interligação por terra, e cujos arranjos produtivos sempre foram voltados para o além-mar ${ }^{8}$ Nas palavras de Gilberto Freyre,

no Brasil o fenômeno sociológico e cultural como que repetiu o geográfico: sociológica e culturalmente desenvolvemo-nos em ilhas e estas em arquipélagos ou numa enorme ilha-continente. [...] Ilha e continente ao mesmo tempo. Ou ilhas e continente. Um arquipélago sociológico ou cultural de proporções continentais. ${ }^{9}$

O insulamento secular dos sertões de norte a sul somente começou a se dissolver a partir do surto de expansão da malha de transportes e comunicações dos anos 1870-1890, que deflagrou a integração das partes desmembradas do espaço-nação num corpo territorial mais ou menos coeso. A extensão de ferrovias, estradas de rodagem e cabos telegráficos além da zona litorânea, conquanto ainda preservando muito da configuração em "ilhas", transformou regiões até então fora do alcance da expansão capitalista e do poder do Estado, agora diretamente ligadas aos centros políticos e econômicos do país. Levantamentos cartográficos 
cada vez mais frequentes e acurados - baseados em triangulação geodésica e, a partir dos anos 1940, empregando equipamentos aerotransportados - prepararam a proliferação de uma rede de vias terrestres e aéreas que unificou pela primeira vez o arquipélago sociocultural num protótipo de continuum nacional, com a diminuição das distâncias relativas e o incremento das velocidades das trocas internas.

No terceiro quartel do século XX, período de Grande sertão: veredas e $A$ pedra do reino, o desenvolvimento das telecomunicações e a construção de aeroportos e rodovias através do centro do país e da Amazônia afinal terminaram de confundir as fronteiras entre cidade e sertão. As vastidões intratáveis do interior foram incorporadas com ferocidade pelo espaço do capital e sujeitas a seu "tempo explosivo" de reprodução. As temporalidades cíclicas das culturas sertanejas se repontuaram pelo compasso das crises periódicas de superprodução e "destruição criativa" características da dinâmica territorial do capital e sua "aniquilação do tempo por meio do espaço", com dramáticas consequências geográficas na periferia do sistema. ${ }^{10}$ Empurrados pela técnica urbana, os limites do sertão - essa categoria espacial mutante que resume a enorme variedade etnológica e mesológica do cerrado, da caatinga e da floresta tropical - se deslocaram rapidamente para o oeste e o norte com o patrocínio entusiasmado do Estado brasileiro. A fronteira agrícola avançou sobre biomas antes intocados, e desmatamento se tornou sinônimo de ordem e progresso.

$\mathrm{Na}$ cruel modernização do sertão, os estratos rurais marginalizados - indígenas, exescravos e seus descendentes, além de colonos imigrantes repelidos pelo latifúndio - foram, na melhor das hipóteses, deslocados como gado para as cidades. Em $O$ encontro marcado, livro eminentemente urbano, esse trágico devir-sertão de nossas capitais aparece apenas de relance, mas faz questão de exibir toda a sua corporeidade flagelada.

\begin{abstract}
Mas, vejam só esse espetáculo. Era uma leva de retirantes dormindo debaixo do Viaduto. Haviam desembarcado na estação, não tinham para onde ir. Mais de cinquenta famílias: homens magros, sujos, mulheres de olho fundo e cabelo desgrenhado, crianças encardidas e seminuas, trouxas de roupa, esteiras, baús, promiscuidade, mau cheiro, abandono. ${ }^{11}$
\end{abstract}

Em poucas décadas, a composição dos fluxos migratórios com a explosão demográfica ocasionada pela imigração e a diminuição das taxas de mortalidade transformou o magro conjunto de centros urbanos do país num complexo de metrópoles e centros regionais que espraiou a técnica moderna sobre territórios anteriormente (des)ocupados pelo sertão. Em 1913, por exemplo, São Paulo mal somava 400 mil habitantes, enquanto o Rio de Janeiro chegava a seu primeiro milhão. Em 1950, essas cidades já possuíam, respectivamente, 2,2 milhões e 2,4 milhões de habitantes.

Cortadas por novos trilhos e avenidas, as capitais do país sofreram reformulações espetaculares em seus antigos setores habitacionais, fabris, administrativos e comerciais. A construção planejada de novas cidades-sede da hierarquia política a partir dos anos 1890, como Belo Horizonte, Goiânia e Brasília, simbolizou a aliança dos capitais privados com o Estado para a conquista de territórios sertanejos até então considerados inaproveitáveis - e a incorporação de suas massas de subproletários aos exércitos de reserva de mão-de-obra urbana, a que se juntaram milhões de imigrantes europeus, levantinos e orientais.

Já nos anos 1900, com as políticas higienistas e racistas de "bota-abaixo" na antiga capital da República, formaram-se as primeiras aglomerações de barracos nos morros do Rio 
de Janeiro. Os retirantes dos sertões do arquipélago brasileiro e seus descendentes foram relegados a bolsões periféricos semelhantes aos bantustões da África do Sul sob o apartheid. Começava o tempo das "cidades partidas", subproduto trágico da clivagem entre casa-grande e senzala que continuou a dominar a história social do país ao longo de sua modernização conservadora.

O devir-cidade do sertão e o devir-sertão da cidade constituem os principais vetores da travessia dos territórios do espaço-nação pelo romance novecentista. ${ }^{12} \mathrm{O}$ espaço urbano, cerradamente povoado e perversamente planejado, se imiscuiu na cenografia dos narradores na mesma razão em que novos sertões desbravados se ofereceram à exploração ficcional.

Os espaços engendrados pelo romance, quando dispensados de funcionar como invólucros inertes dos conteúdos narrativos, possuem o mesmo direito de cidade dos espaços da realidade física. As ações e objetos de um livro - ou, nos termos de Boris Tomachevski, seus episódios (entendidos como complexos de ações), utensílios e personagens ${ }^{13}$ - compõem um espaço tão "real" quanto o espaço geográfico, conforme definido por Milton Santos. ${ }^{14}$ Nos domínios da física como nos da geografia e da literatura, séries de eventos locais se integram em matrizes de posições cuja configuração interna em campos de força e movimento é condição suficiente para que sejam denominados "espaços".

Corpo de papel circulante no espaço da realidade física, o romance também pode ser considerado um macroato de fala que intervém na prosa do mundo como ação estéticoideológica. ${ }^{15} \mathrm{E}$ essa ação se efetua através do balanço posicional resultante da configuração espacial das vozes componentes da macrofala narrativa. Em maior ou menor grau (mas não se deve sustentar liminarmente que essa relação se dê apenas por diferenças de grau), o espaço produzido por tal balanço ou rearranjo emprega a geografia do real como paisagem ou cena enunciativa - ou melhor, dada a multidimensionalidade presumível dessa relação, como uma das paisagens, um dos panos de fundo que delimitam a enunciação literária. Um dos problemas-chave para a crítica é que, ação estético-ideológica, a literatura atua como vetor de mudança do próprio sistema de ações, objetos e posições de que é parte, procurando a todo momento deslocar o quadro dimensional que lhe serve de moldura. Nessa situação singular da literatura no espaço, um romance é apenas mais um corpo físico imerso no sistema de eventos da realidade, mas também um macroato de fala que afeta a subjetividade que percebe e concebe o sistema ao interferir nos "modelos gerais de significação e de representação".16 $\mathrm{O}$ objeto-ação literário está em todas as partes, o que também quer dizer em lugar nenhum, posição aliás comparável à paratopia do escritor.

Assim, o estudo da geografia do romance deve se propor a "estudar não somente uma relação unilateral (espaço-literatura), mas uma verdadeira dialética (espaço-literatura-espaço), o que implica que o espaço se transforma, por sua vez, em função do texto que anteriormente o havia assimilado". ${ }^{17} \mathrm{O}$ texto literário é indissociável de seu contexto geográfico ${ }^{18}$ e da gestão espacial desse contexto, que se efetua na fronteira entre a cenografia da enunciação e a arquitetura virtual dos mundos simulados. A porosidade da fronteira é muito variável. Os lugares fingidos exibem diversas gradações de semelhança com lugares da realidade histórica. 
Em Esaú e Jacó, por exemplo, numerosas ruas e acidentes geográficos do Rio de Janeiro das décadas de 1870 e 1890 integram a topografia da trama, na qual são reencenados acontecimentos históricos como a Abolição, a Proclamação da República e o Encilhamento. Em A pedra do reino, a vasta maioria dos míticos topônimos do Cariri e do Pajeú citados no memorial de Pedro Quaderna também pode ser encontrada nos mapas do sertão paraibano e pernambucano. Por outro lado, bem pouco da rarefeita São Paulo de Serafim Ponte Grande aparece nas plantas da capital na década de 1920.

De todo modo, como assinala Gabriel Zoran, é contraproducente traçar paralelos, mesmo metafóricos, entre os espaços da ficção e a realidade sensória. Apesar de compartilharem o mesmo nível de "realidade", esses dois campos não possuem homologia estrutural, pois são fundamentalmente distintos no que respeita aos agenciamentos de sua percepção. ${ }^{19}$ Pois, como na música e no cinema, a produção do espaço pelo romance se dá inexoravelmente na sucessão do tempo - em contraste com a experiência imediata dos sentidos. A espacialidade do romance pende no fio amolado da navalha temporal que alinhava passado e futuro no tecido impermanente da memória da leitura - através da qual o leitor, coenunciador, deriva os horizontes de expectativas possíveis para o futuro da narração no espaço a partir do conhecimento geográfico acumulado ao longo do pacto enunciativo. Delimita-se assim um espaço de experiência, o espaço da ficção. ${ }^{20}$

Não se trata, portanto, de promover o mero rastreamento cartográfico dos personagens, ações e objetos dos textos romanescos em mapas contemporâneos da publicação ou da narração - mesmo porque muitos romances do século XX não se fixam numa topografia determinável, ou inventam suas próprias utopias/distopias. Tal mapeamento, ademais, se restringe à topografia do espaço reconstruído, menosprezando a dimensão decisiva de suas configurações cronotópicas e textuais. Para avançar sobre os sertões internos da narrativa, é necessário delinear uma visão funcional da produção do espaço entre as camadas do texto no tempo.

Num ensaio de 1984, vinte anos antes do boom geocrítico, Gabriel Zoran realiza uma notável sistematização das simulações espaciais da ficção. ${ }^{21}$ Intervindo num debate multipolar que reúne do subjetivismo poético de Gaston Bachelard ao rigor semiológico de Julia Kristeva, o crítico israelense procura estabelecer uma língua comum para a análise dos mundos reconstruídos por meio de sua estratificação do espaço ficcional em três níveis de experiência.

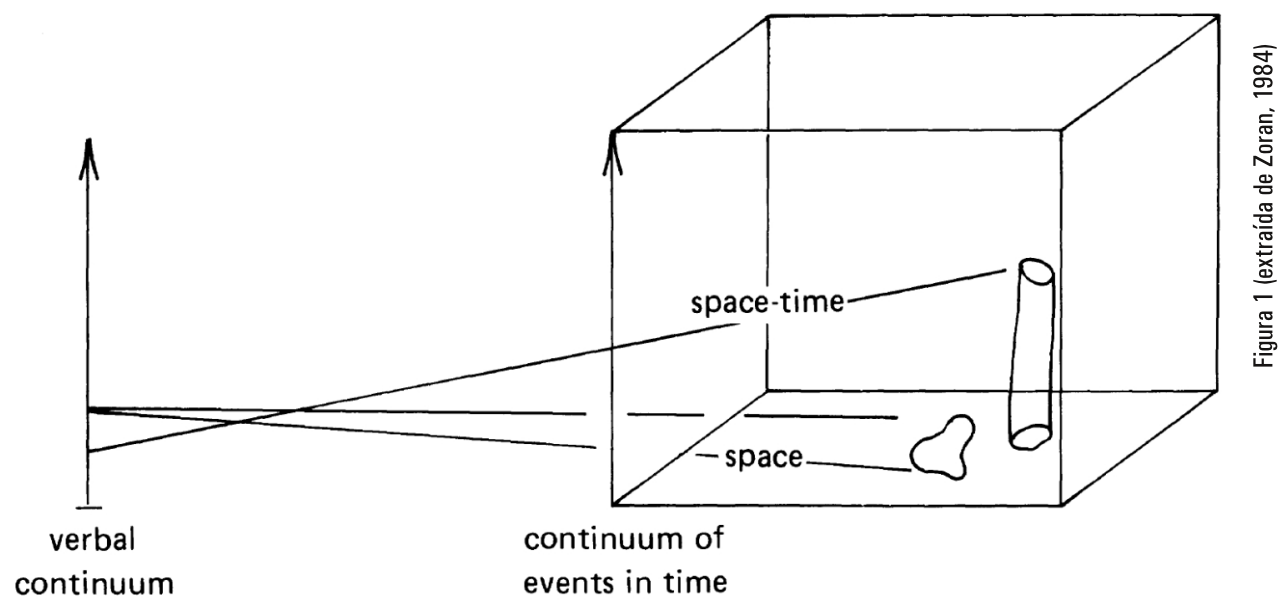


No nível topográfico, o espaço é percebido como "entidade estática", sincrônica. A topografia do espaço simulado em geral pode ser desenhada em cartas e/ou diagramas bidimensionais nos termos das distâncias relativas entre os lugares de episódios e personagens - eventualmente conectadas a lugares, pessoas e objetos da topografia da realidade física. $\mathrm{Na}$ Figura 1, corresponde à porção plana delimitada na face inferior do cubo.

Composição entre a sincronia da topografia e a diacronia da diegese, o nível cronotópico é a "estrutura imposta ao espaço por eventos e movimentos, isto é, pelo espaço-tempo".22 $\mathrm{Na}$ sucessão temporal das trajetórias internas da trama, é a instância em que se processam as interações entre objetos e personagens, reguladas por seus respectivos regimes de deslocamento e estase. Em outras palavras, o nível cronotópico pode ser descrito em termos de vetores de velocidades e movimentos relativos entre os agentes da narrativa no fluxo temporal da leitura. Na Figura: cA, é representado pelo volume que se estende no eixo do tempo a partir do plano topográfico.

No nível mais imediato de contato, o textual, atua "a estrutura imposta ao espaço pelo fato de que é significada no interior do texto verbal".23 Concerne à hierarquização dos lugares da narração entre o "aqui" da enunciação e o "lá" do resto do mundo do texto. As transições entre essas posições determinam a projeção dos níveis anteriores no continuum verbal, não necessariamente na sequência linear da cronologia da leitura, como nos flashbacks. As velocidades da narrativa, portanto, não dizem respeito somente à densidade de eventos, ou às durações relativas da trama. Contam também os modos de articulação entre os blocos espaciais do texto, assim como a dinâmica textual dos temas e motivos.

É no nível textual que se articula a visibilidade das vozes da composição. Pois existe uma dupla visibilidade no espaço ficcional: a das imagens espaçotemporais formadas pela simulação topográfico-cronotópica, em seus variados graus de determinação; e a das vozes narrativas em sua distribuição posicional na tessitura do texto, que também poderia ser denominada audibilidade. Para usar uma metáfora musical, é no nível textual que se consuma o arranjo das massas corais e das vozes solistas no palco da enunciação, distribuídos segundo o "aqui" e o "lá" determinados pelo entrelaçamento dos três níveis do espaço fingido.

Unidade básica do nível textual, o campo de visão, definido como "aquilo que se percebe como sendo o "aqui", resulta da "combinação do momento presente da leitura com a síntese da memória". ${ }^{24}$ É o presente instantâneo do espaço ficcional mais o conhecimento acumulado de sua geografia. O ponto de vista, assim, funciona simultaneamente como um ponto de interseção dos campos de visão e um ponto de projeção das vozes narrativas.

Um conjunto de campos de visão relacionados no espaço total do mundo reconstruído constitui um complexo espacial. Essas espécies de "arranjos locais" da narrativa formam clareiras de determinação em meio às zonas de obscuridade que ficam além do alcance do complexo de campos de visão, mas que igualmente participam da produção do "espaço total" ao impor limites ao mundo simulado. "O espaço total é uma imensa área de indeterminação e escuridão relativa, no qual o complexo espacial aparece como uma ilha de determinação e claridade". ${ }^{25}$

Os três níveis, claro está, participam simultaneamente da totalização dos efeitos espaçotemporais da leitura. "O leitor não começa no nível textual e depois passa para os demais, ou vice-versa; em vez disso, ele está continuamente se movimentando entre os três 
níveis e, ademais, percebe-os ao mesmo tempo sem poder separá-los". ${ }^{26}$ A infinita variabilidade combinatória entre os níveis do espaço do romance possibilita uma não menos ampla gama de arquiteturas narrativas cuja percepção é independente das cronologias da realidade física.

A delimitação de fronteiras convencionais entre os níveis de operação das topologias narrativas é a principal virtude da sistematização de Zoran. A fixação de conceitos funcionais como "campo de visão" e "complexo espacial" contribui sensivelmente para a análise geocrítica, cujo apego aos níveis topográfico e cronotópico amiúde ignora a dimensão do nível textual, instância decisiva em que se processa a corporificação dos pontos de vista e sua vocalização em tropos espaçotemporais.

A partir da hipótese de que o romance brasileiro atingiu seu apogeu estético e político no período crítico da interpenetração dos polos espaciais sertão e cidade no século XX, é possível pensar que esse gênero ficcional tenha se instituído como o mais propício à figuração da continentalização do território em "ilhas" do espaço-nação (e das crises dessa continentalização) porque a própria totalização dos efeitos espaçotemporais da narrativa longa propõe uma espécie de continentalização dos complexos espaciais dos campos de visão na memória da leitura.

No caso de Grande sertão: veredas, a analogia é conveniente: movida pela necessidade de estabelecer o sentido final dos eventos da existência, uma mesma voz, conquanto elasticamente modulável, unifica os numerosos arranjos locais da travessia do Sertão ao tentar resolver (ainda que de modo precário) as dissonâncias entre a ordem de Deus e a desordem do diabo. ${ }^{27}$ Contudo, na fala elusiva e digressiva de Riobaldo a continentalização proporcionada pelos efeitos espaciais da narrativa longa também não deixa de ser questionada. Em Serafim Ponte Grande, a interconexão dos complexos espaciais das memórias sentimentais do protagonista é liminarmente negada. $\mathrm{O}$ estilhaçamento da narrativa pela atrição violenta das vozes solistas com a massa amorfa do espaço total de São Paulo e do mundo ressalta o devirilha da capital burguesa em que vence sempre o mais voraz. Em $O$ encontro marcado, outro exemplar combativo de romance urbano (conquanto bem mais comportado que a prosa de Oswald), as sucessivas rupturas e recomeços da trajetória de Eduardo Marciano entre Belo Horizonte e o Rio de Janeiro reiteram a inviabilidade retórica e afetiva da continentalização dos eventos da existência num contexto de aceleração das mudanças.

Para engendrar seus efeitos de continentalização e descontinentalização, a partir do século XX o romance brasileiro adota os mapas cada vez mais acurados do Brasil como lugares privilegiados de enunciação. Não por acaso, a manipulação cartográfica do espaço fíccional passou a figurar na agenda dos grandes romancistas a partir do advento de mapas cada vez mais abrangentes e precisos das capitais e do interior, que foi concomitante à sedimentação da identidade nacional promovida pelo Estado republicano e propagada por suas instituições de ensino. ${ }^{28}$

Os livros definidores da nacionalidade literária e linguística passaram a funcionar como instrumentos complementares dos mapas políticos expostos nas aulas de geografia. A produção 
de cartas cientificamente precisas do Brasil e o rápido desenvolvimento da cartografia aérea foram etapas do mesmo projeto de conquista territorial, que propulsionou a veloz continentalização das ilhas socioculturais até então rodeadas de mar e/ou sertão por todos os lados. Munidos de mapas, instrumentos por excelência do controle do espaço, os narradores de fronteira do século XX planejam seus livros como aparatos de sabotagem às espacializações brutais do capital e do Estado - na mesma época em que a palavra geopolítica entra no vocabulário militar. ${ }^{29}$ Em posição de batalha, empregando as mesmas armas geoespaciais das instituições sociais, políticas e literárias que alvejam desde suas paratopias, os grandes romancistas não aceitam a vassalagem imposta à produção literária pelo triunfo repetitivo das convenções retóricas da ficção realista e dos decalques audiovisuais da "realidade", abrindo o espectro enunciativo de seus livros ao ruído de fundo das vozes marginalizadas no espaço total da língua e da literatura.

Segundo David Harvey, no contexto da alta modernidade capitalista os artefatos estéticos de invenção almejam produzir regimes espaçotemporais alternativos às espacializações da realidade administrada, injetando sinais de interferência e indeterminação entre os ritmos estereotipados da reprodução do capital literário e do controle social. Ruídos, distorções, engasgos e vociferações em meio às vozes hegemônicas; coros de reafirmação e louvor no caso da literatura de repetição. Os romancistas de fronteira inventam suas próprias rotinas de produção de valor estético ao reconfigurar as cacofonias da realidade conforme novas regras de espacialização do tempo, nas quais se recombinam e reconfiguram as posições consagradas das vozes do contexto da enunciação. A despeito da vigência de certas regras de verossimilhança da física do cotidiano, os objetos, ações e personagens do romance moderno, dispostos na topografia dos mundos imaginados e no fluxo textual da simulação cronotópica, são submetidos a regimes de permanência e deslocamento amiúde concorrentes, contrários, hostis à experiência convencional dos sentidos. Por outro lado, os romances também são capazes de imitar os esquemas da literatura e da realidade banais para desnudar sua tacanhez num registro irônico. Trata-se do remanejamento crítico dos processos materiais e discursivos da realidade e seus padrões de reificação pelo espaço-tempo do romance.

No Brasil do século XX, as transformações do espaço geográfico embaralharam as distâncias relativas das categorias "sertão" e "cidade" ao promover massivos deslocamentos das posições e zonas de ação dos corpos falantes no território do espaço-nação. Esse remanejamento biopolítico, como sublinha Deleuze sobre o problema da posição da voz, "implica bem a ideia de orientações [...] e de pontos cardeais, de organizações desta vida segundo coordenadas e dimensões variáveis ou cambiantes, toda uma geografia, toda uma geometria das dimensões vivas". ${ }^{30}$ Nesse sentido, o horizonte geográfico do romance de fronteira do Novecento é o questionamento das posições consagradas ou das novas posições assumidas - e no limite, das próprias noções de posição e dimensão que subjazem à geometria common sense do real e seus decalques literários. Nas ficções "sertanejas" selecionadas para esta leitura, os alvos primários são a uniformização destruidora dos falares e ambientes ecoculturais regionais pela invasão da técnica urbana, bem como pelo regionalismo de repetição. Na alça de mira dos romances "urbanos", a usurpação dos lugares identitários da cidade e a estrangulação da língua escrita pelos chavões beletrísticos talhados ao gosto da pequena elite de leitores brancos num país de vasta maioria não branca e analfabeta. A violenta reconfiguração territorial da cidade e do sertão pela aceleração do "tempo explosivo" do capital é a outra face da moeda falsa dos produtos literários regressivos, camisa de força da qual o romance de ponta tenta escapar ao propor novos padrões de medida e, portanto, de valor. 
Essa crise emancipadora é encenada em Serafim Ponte Grande, terminado em 1928 segundo o Oswald de 1933, pela rarefação da topografia, pela aceleração das cronotopias e pela heterogeneidade da série de complexos espaciais. $\mathrm{O}$ mundo inflamado do romance oswaldiano, que inclui cenas de batalha alusivas ao levante tenentista de 1924, é o campo de operações da "tática do choque" e da "violação das continuidades esperadas"31 empregadas como fogo de barragem pela vanguarda modernista para estabelecer suas cabeças de ponte no território estético da "digestão bem-feita de São Paulo". ${ }^{32}$ O lastro enunciativo das perambulações fragmentárias da narração através da capital paulista e do mundo são as flutuações do preço internacional da saca de café. A inconsequência da burguesia paulista está prestes a se chocar contra o muro anunciado da superprodução. Mas, em 1933, o devir-ilha da contrarrevolução separatista de São Paulo já foi fragorosamente derrotado pela continentalização forçada do governo central. Oswald, ex-aristocrata antropófago e agora "homem do povo", não deixa de lamentar o colapso da belle époque da cidade-ilha diretamente conectada (via porto de Santos) aos confortos civilizados da Europa: "Necrológio da burguesia. Epitáfio do que fui". 33

Em São Bernardo, ${ }^{34}$ publicado no ano seguinte ao da primeira edição de Serafim Ponte Grande, o arruinado fazendeiro Paulo Honório e sua narração vociferante constituem uma áspera demonstração ficcional da impossibilidade última de o "tempo explosivo" da cidade subjugar por completo os ritmos arcaicos do sertão. Nesse brutal romance "regionalista" que detona a toada tardo-romântica de certo regionalismo de 1930, o sertão está sempre onde o narrador está, espreitando-o ao modo de baixo contínuo em todas as passagens da trama, como não deixa de lembrá-lo o canto lúgubre das corujas na capela da fazenda arruinada. Revelador da operação basal desse devir-sertão da modernização da fazenda São Bernardo é o episódio da viagem de Paulo Honório a Maceió para surrar um jornalista maledicente. O sertão responde violentamente ao jugo continentalizador da cidade litorânea, e, inconformado com a posição que lhe é reservada no novo continente da política e do capital, insiste em atravessar a cada passo a geografia da fazenda modernizada, onde provoca violência, morte e bancarrota. Em Graciliano, o sertão nunca cessa reivindicar seu protagonismo dissonante no desconcerto das vozes da modernização e da urbanização.

Nos grandes artefatos romanescos do século, novos padrões de velocidades atravessam em contravapor os cronogramas de acumulação e controle da cenografia socioeconômica. Em São Bernardo e Serafim Ponte Grande, a história da ascensão e queda do liberalismo agrário da República Velha é a paisagem política inescapável das ondas de choque projetadas pelas vozes insolentes de Paulo Honório e Serafim Ponte Grande em meio à voragem revolucionária da técnica moderna e suas crises periódicas de "destruição criativa". Em Grande sertão: veredas e $A$ pedra do reino, a recuperação arqueológica das vozes ancestrais do sertão e seu rearranjo alegórico manifestam um enfático clamor de resistência à invasão uniformizadora do sertão pela cidade. $\mathrm{O}$ vale-tudo da internacionalização capitalista do país é sua contraparte geopolítica. Em Esaú e Jacó e $O$ encontro marcado, as transformações da cidade indicam a impermanência dos esquemas da tradição diante dos novos ventos de liberalização das trocas e dos costumes. São livros escritos contra a destruição física e simbólica das vozes e lugares marginalizados na conquista do território do espaço-nação segundo seu reposicionamento crítico nos mapas literários.

Talvez por isso, o mundo me pareça uma mesa e a vida um jogo, onde se cruzam fidalgos Reis de Ouro com castanhas Damas de Espada, onde passam Ases, Peninchas e Coringas, governados pelas regras desconhecidas de alguma velha Canastra esquecida. ${ }^{35}$ 
No opus magnum de Suassuna, a estratégia de resistência coincide com a laboriosa construção textual do castelo literário de Pedro Quaderna, o próprio romance que se escreve entre a horizontalidade da mesa de baralho, na sincronia geométrica da topografia do sertão do Cariri, e a verticalidade da Pedra do Reino, ruína ou cronótopo da passagem do tempo histórico-geológico. À diferença de Serafim/Oswald com seu mapa enluarado de São Paulo no alto da torre do mosteiro de São Bento - ou mesmo de Paulo Honório no episódio do extermínio das corujas no campanário da capela da São Bernardo -, nada do que Quaderna avista desde seu elevado posto de observação na Cadeia Velha da Vila Real da Ribeira do Taperoá está dentro de sua zona de ação imediata. Entretanto, rapsódia negro-tapuia e flamengo-ibérica narrada desde uma alusiva prisão ditatorial no alto sertão, o alentado depoimento em primeira pessoa desse matreiro rei-prisioneiro se constrói como uma textualização alegórica da história laboriosamente planejada para, ao mesmo tempo, 1. provar ao Corregedor da justiça inquisitorial do Estado Novo a inocência do bibliotecário e acadêmico Pedro Diniz Ferreira-Quaderna dos crimes de sangue e subversão política que lhe são imputados; 2. atestar junto à Academia Brasileira, "esse Supremo Tribunal das Letras", ${ }^{36}$ sua condição de "gênio da raça brasileira" e assim 3. reconsagrar a fortaleza imortal da dinastia d'El Rei d. Pedro IV, o Decifrador, enquanto 4. dá volumoso corpo textual a uma miríade de vozes da história sufocadas pela voz hegemônica dos vencedores de sempre, ação especialmente arriscada naquele 1971 de chumbo. Assim, o lugar de enunciação do romance é sempre a bizarra formação geológica na fronteira entre a Paraíba e Pernambuco, assento do Trono real, mas também, por sinédoque, todas as pedras, lajedos, serras e rios sagrados em todos os tempos do território do Estado-nação, ou melhor, do Quinto Império quadernesco. O Século do Reino é aqui e agora.

Esse deslocamento escatológico da narração de Suassuna foi mal recepcionado tanto por setores da esquerda - para quem o movimento armorial e seu apego brasônico sempre soaram reacionários - como pela direita à la dr. Samuel Wandernes, que farejou o potencial subversivo de um romance nordestino contado por um preso político. Sintomaticamente, a despeito de uma boa adaptação televisiva, o livro está hoje (agosto de 2013) esgotado, ${ }^{37}$ sendo somente encontrável em sebos ou como e-book - isto é, aprisionado em telas de cristal líquido ou relegado aos monturos da reciclagem de lixo literário. Porque não redutível a valor de uso pela forja do cânone, perdeu seu direito de existir como artefato físico: carta fora do baralho convertida em lampejo fugaz nas telas de consumo conspícuo do videocapitalismo. Tal achatamento procura obliterar a multidimensionalidade incômoda da voz guerreira de sua majestade, o rei-prisioneiro de Taperoá. No entanto, sobranceiro como as torres da Pedra do Reino e chão como o Lajedo sagrado de d. Diniz-Quaderna, o livro sobrevive como um impressionante castelo de cartas erguido no coração do sertão contra a blitzkrieg das cidades.

Grande sertão: veredas perdura quase sessenta anos depois da primeira publicação como uma espetacular realização ficcional da visão benjaminiana sobre a grande cidade que devém selva selvaggia, onde o menor ruído e a menor franja de luz ou sombra podem fazer a diferença entre a perdição e o encontro.

Saber orientar-se numa cidade não significa muito. No entanto, perder-se numa cidade, como alguém se perde numa floresta, requer instrução. Nesse caso, o nome das ruas deve soar para aquele que se perde como o estalar do graveto seco pisado, e 
as vielas do centro da cidade devem refletir as horas do dia tão nitidamente quanto um desfiladeiro. ${ }^{38}$

O sertão no romance rosiano, segundo Wili Bolle, já se apresenta transfigurado pela experiência da modernidade propagada através das ruas das novas cidades tentaculares do Brasil. Índice evidente do forte devir-cidade de Grande sertão: veredas é a conformação topográfico-cronotópica dos eventos recontados pelo ex-jagunço Riobaldo, que desenha emaranhados de trajetos imprevisíveis no mapa das veredas de Minas Gerais, Goiás e Bahia. ${ }^{39}$ É como se esses caminhos errantes e, no nível textual de seu encadeamento em complexos espaciais, repletos de rupturas e indeterminações, correspondessem à deriva através de uma urbs labiríntica, explorada pela prosa flâneuse de Riobaldo.

Como os mapas a seguir procuram mostrar, a espacialidade conflagrada do sermo riobaldinus e seus múltiplos desvios e atalhos têm como pano de fundo intertextual a geodesia planetária do livro-irmão, Corpo de baile. ${ }^{40}$ As sete novelas, também publicadas em 1956, constituem um lugar privilegiado da enunciação de Riobaldo ao demarcar importantes complexos espaciais de sua memória topográfica. Ademais, as sete novelas fornecem ao embrejamento da voz do ex-jagunço um contraponto apolíneo, encenado pela geodesia calculada dos sete principais cenários. O abismo temático e formal inventado pelos dois livrosirmãos se visualiza nitidamente no confronto entre as topografias das respectivas tramas. Escritos e publicados quase ao mesmo tempo, esses dois livros e seu jogo entre ordem e desordem assinalam a posição de Rosa a cavaleiro entre a vanguarda modernista urbana, cientificista e planificadora, e o matagal primitivo das palavras e estórias do sertão.

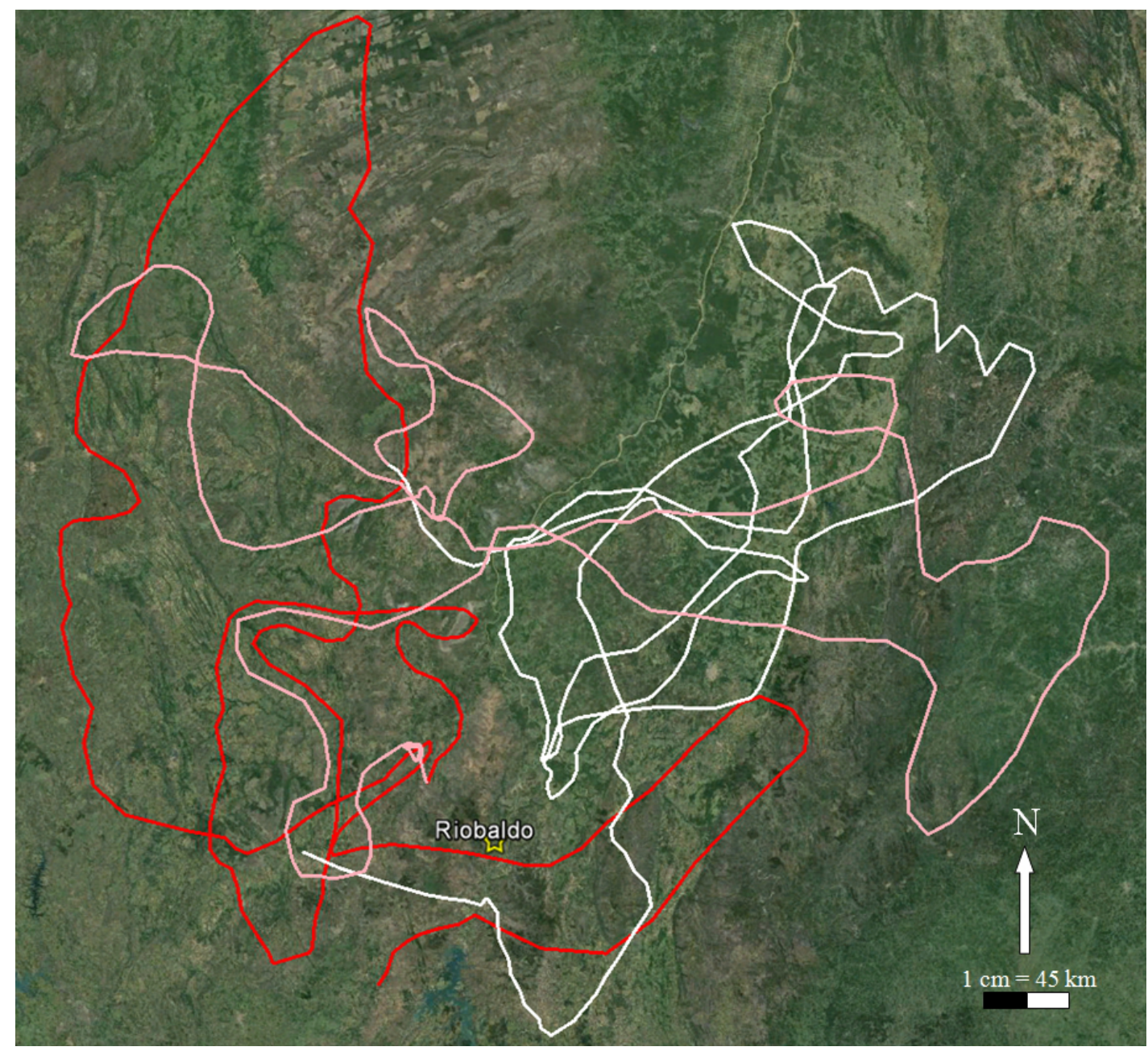

Figura 2 - Trajetória de Riobaldo em Grande sertão: veredas41 
Grande sertão: veredas explode a topologia em arquipélago das sete novelas e desborda sua topografia para o nordeste de Minas e partes de Goiás e da Bahia. As curvas retorcidas da fala ao rés do chão de Riobaldo fazem rizoma - redemoinho - em contraste com a reta inclinada que ordena o olhar aerofotogramétrico do discurso indireto livre predominante na narração de Corpo de baile. A composição entre o $\mathrm{S}$ da estrada das fazendas-planetas de "O recado do morro" e a loxodrômica Saturnino-Apolinário-Mutúm é um signo do confronto entre reta e curva que domina as espacializações de Rosa em 1956. O olho do mapa e as vozes do chão: o Ser do sertão e o Vir-a-Ser da cidade $^{43}$ se entrelaçam em permanente tensão espacial nesse par de livros que compõe o alfa-ômega da narrativa rosiana.

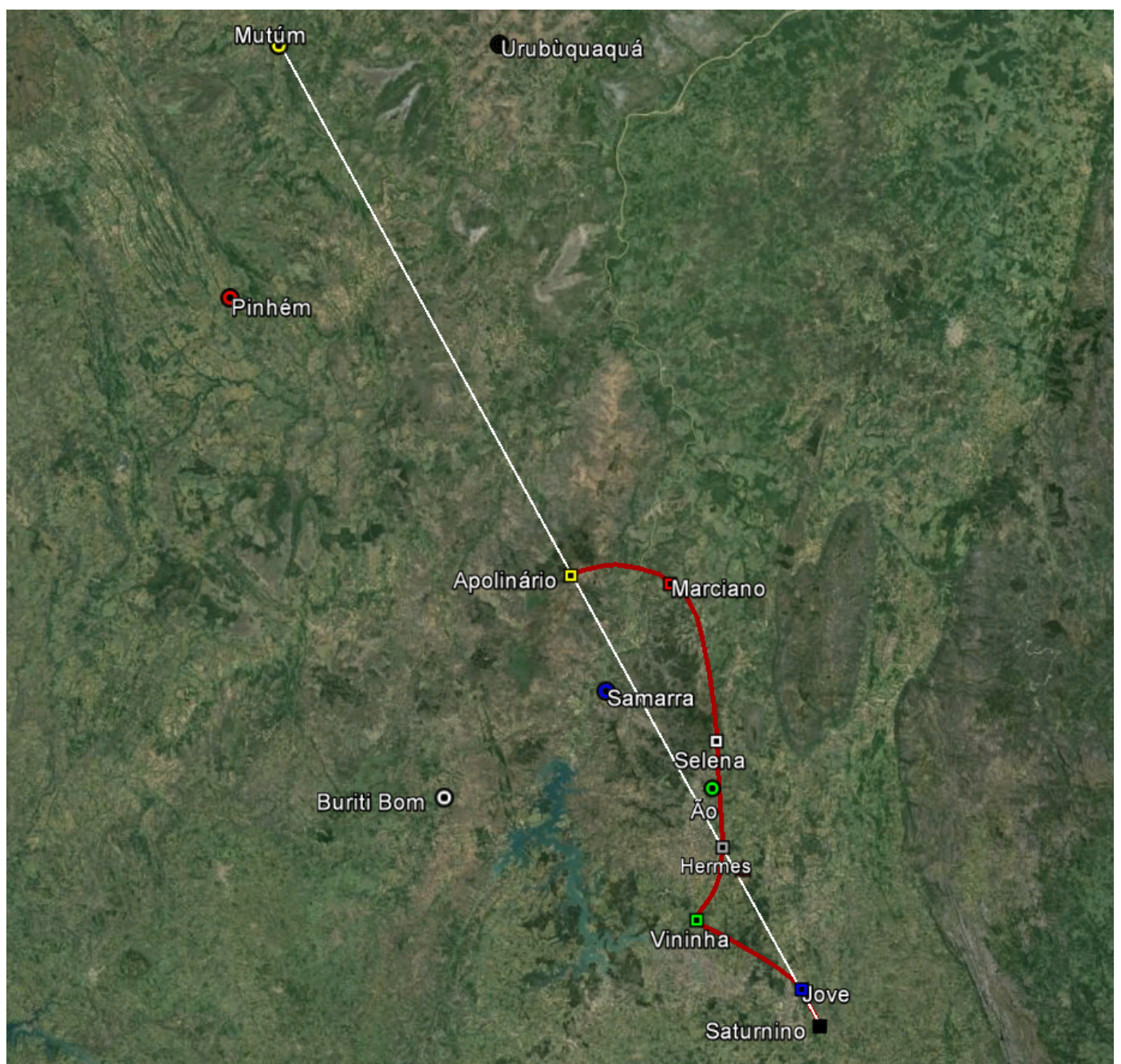

Figura 3 - Topografia de Corpo de baile com o S da trajetória da viagem da comitiva de "0 recado do morro" em torno da loxodrômica Saturnino-Apolinário-Mutúm. ${ }^{42}$

Segundo leva a crer a cronologia genética dos volumes publicados naquele annus mirabilis da literatura brasileira, em meados de $1954^{44}$ Rosa desnuda-se do aparatoso arsenal de epígrafes, índices, rodapés e outros paratextos de Corpo de baile para se dedicar exclusivamente à afinação da monodia polifônica de Grande sertão: veredas. Assegurado o domínio das posições estratégicas do noroeste de Minas pela topografia geodésica das sete novelas, Rosa se lança à aventura de inventar um novo Sertão a partir das modulações errantes de "uma voz e nada mais" (como no livro de Mladen Dolar ${ }^{45}$ ), puro melisma da mobilidade. 


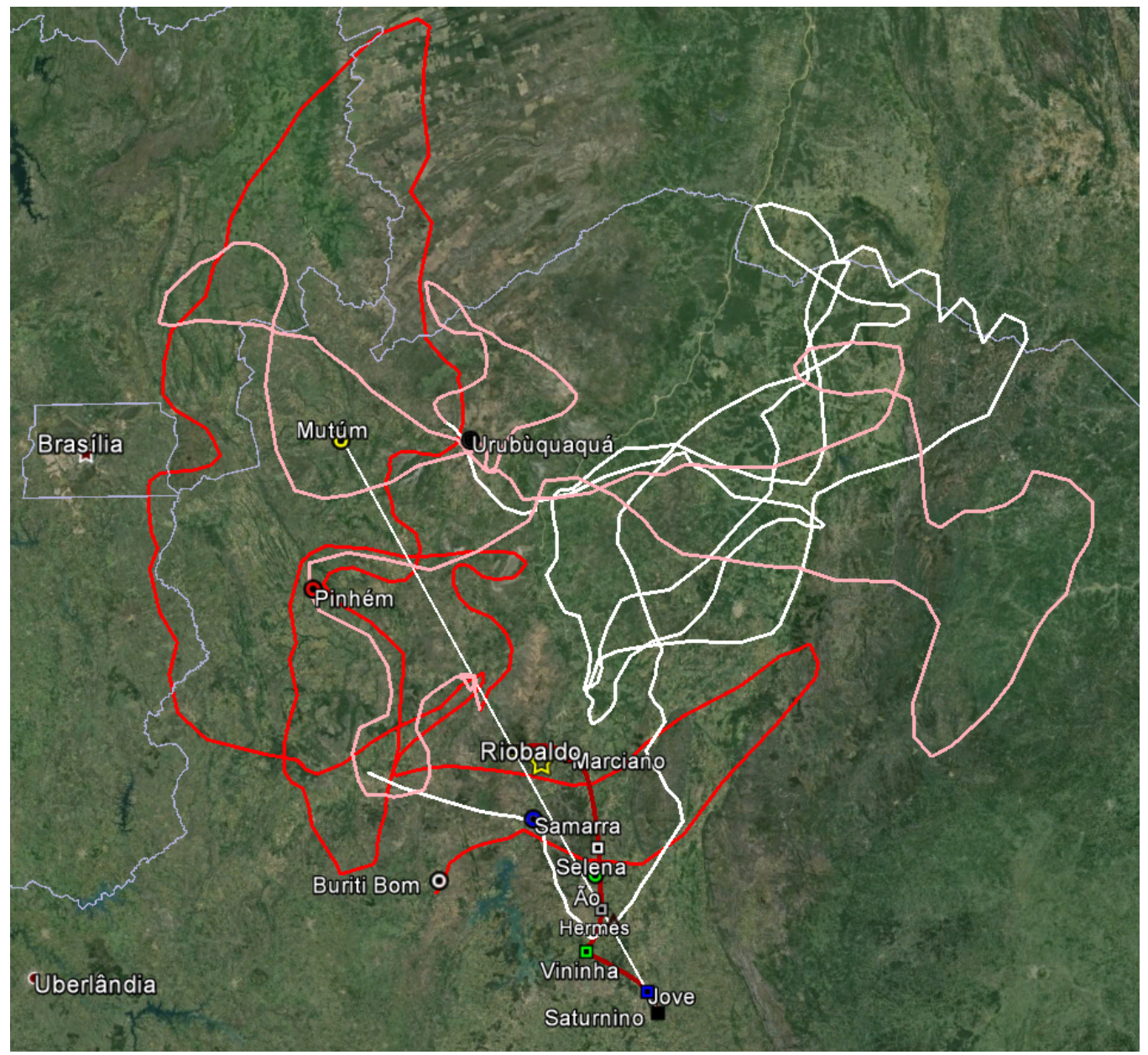

Figura 4 - Corpo de baile e Grande sertão: veredas no mapa dos ser tões rosianos.

Renunciando às suntuosas árias e corais de Corpo de baile, num voto de pobreza análogo ao dos comandantes militares que precisam abandonar suas melhores peças de artilharia para aumentar a velocidade da tropa, o escritor cordisburguense coloca uma faca jagunça nos dentes da enunciação exploratória para desafiar a imobilidade das posições consolidadas nos mapas da narrativa brasileira. É como se, percebendo pelo avesso a reificação e a homogeneização do espaço proporcionadas pelas cartas desenhadas nas fortalezas burocráticas do Estado e do capital, Rosa precisasse retornar (não sem o intensivo auxílio desses mesmos mapas) à época em que os mapas de Minas Gerais ainda não existiam, apenas os roteiros de topônimos de rios e montanhas recontados pela fantasia dos aventureiros das brenhas. Daí, também, a extrema importância dos nomes no espaço conflagrado do romance, com seu condão musical de invocar o "poder do lugar". 46

Com o signo heráldico das sete novelas tatuado na armadura de couro, Riobaldo - esse cavaleiro andante dos ritmos encantatórios da língua brasileira - no entanto jamais dispensa a supremacia aérea instrumentalizada pelo manejo de mapas aerofotográficos do Sertão e suas acuradas visões do território. O escritor mineiro demonstra desse modo uma assombrosa maestria na conjugação entre a "guerra de posições" da geometria em arquipélago das sete fortalezas planetárias das novelas e o redemoinho da "guerra de movimentos" da flânerie guerrilheira de Riobaldo Tatarana. Os ruidosos volteios das colunas jagunças e a música 
silenciosa da batalha geodésica entre as fazendas-planetas demarcam os lugares fundadores de um novo Sertão na literatura brasileira, reconfigurando suas fronteiras internas e externas - e, no relato movente de Riobaldo, colocando em xeque a própria noção de fronteira. ${ }^{48}$

Também um livro de fronteira e conquista territorial, mas encenado no polo espacial oposto, Esaú e Jacó é um memento literário do Rio de Janeiro e o testamento artístico de Machado de Assis.

No início do século XX, a "haussmannização" do Rio antigo - a demolição do morro do Senado em 1891, o aterro do cais do Porto (a partir de 1900), o avanço final da cidade sobre as encostas do morro do Castelo com a abertura da avenida Central (atual Rio Branco) em 19034, a verticalização do Centro, a instalação dos transportes ferroviários e da iluminação elétrica - foi contemporânea da brutal expansão populacional dos subúrbios. Novos padrões de ocupação territorial e, portanto, novos regimes de subjetividade e literariedade foram instaurados na capital do país, processo geográfico a que a escritura machadiana não se furtou responder.

O cronista João do Rio registra sobre o "bota-abaixo" iniciado pelo prefeito Pereira Passos em 1903 que "a remodelação do Rio de Janeiro [...] alterou não só o perfil e a ecologia urbanas, mas ainda o conjunto das experiências de seus habitantes". ${ }^{49} \mathrm{Na}$ medida em que prolifera seus tentáculos para o interior, a cidade-porto, até então uma ilha de civilização rodeada de mar e sertão por todos os lados, perde seu caráter defensivo de cidadela, tornandose cada vez mais suscetível ao assédio do devir-continente do espaço-nação. O Rio devém sertão, continentalizando-se como selva selvaggia e aspra e forte. "A cidade, que, no passado, era o lugar fechado e seguro por antonomásia, o seio materno, torna-se o lugar da insegurança, da inevitável luta pela sobrevivência, do medo, da angústia, do desespero". ${ }^{50}$

À semelhança do romance de Rosa, a fabulação espacial de Machado reage dramaticamente às metamorfoses de seu contexto geográfico. Entre 1871, data da visita de Natividade à cabocla do morro do Castelo (lugar de fundação da cidadela de Estácio de Sá, em 1567), e a primeira metade dos anos 1890, quando os gêmeos Pedro e Paulo já são deputados federais e termina a cronologia da narração, é a cidade antiga que se despede para ceder lugar às planificações e calamidades da técnica moderna. $\mathrm{O}$ acanhado Rio colonial de Macedo e Alencar dá passagem à metrópole trepidante dos grandes romances urbanos do século XX. Como formulei algures, à maneira de Rosa

um escritor de fronteira, ancorado no realismo oitocentista mas de olhos postos nos
redemoinhos do novo século, Joaquim Maria Machado de Assis está como José da
Costa Marcondes Aires (morador da rua do Catete e diplomata mediador dos
conflitos entre os gêmeos Pedro e Paulo) no ponto médio de uma linha de fuga que
une/separa dois mundos: o Rio antigo insulado no morro do Castelo da pobre cabocla
Bárbara, prestes a ser demolido, e a cidade nova estendida ao longo da praia de
Botafogo do rico banqueiro Santos, a florescente "Barra da Tijuca" de então. ${ }^{51}$

Aires, diplomata mediador dos conflitos territoriais entre os gêmeos Pedro e Paulo, é o olho móvel cuja voz ilustrada determina o "aqui" da enunciação - um "aqui" em vivaz movimento, tensionado pelo "lá" da mudança e da permanência. Nesse jogo de xadrez enunciativo, o "aqui" da literatura e o "lá" da história se sobrepõem quase indistintamente. Flora é o nó articulador e insolúvel da dualidade espaçotemporal antigo/moderno que se expande na cadeia de oposições Pedro e Paulo, Robespierre e Luís XVI, medicina e advocacia, São Paulo e Rio de Janeiro, Império e República etc. 


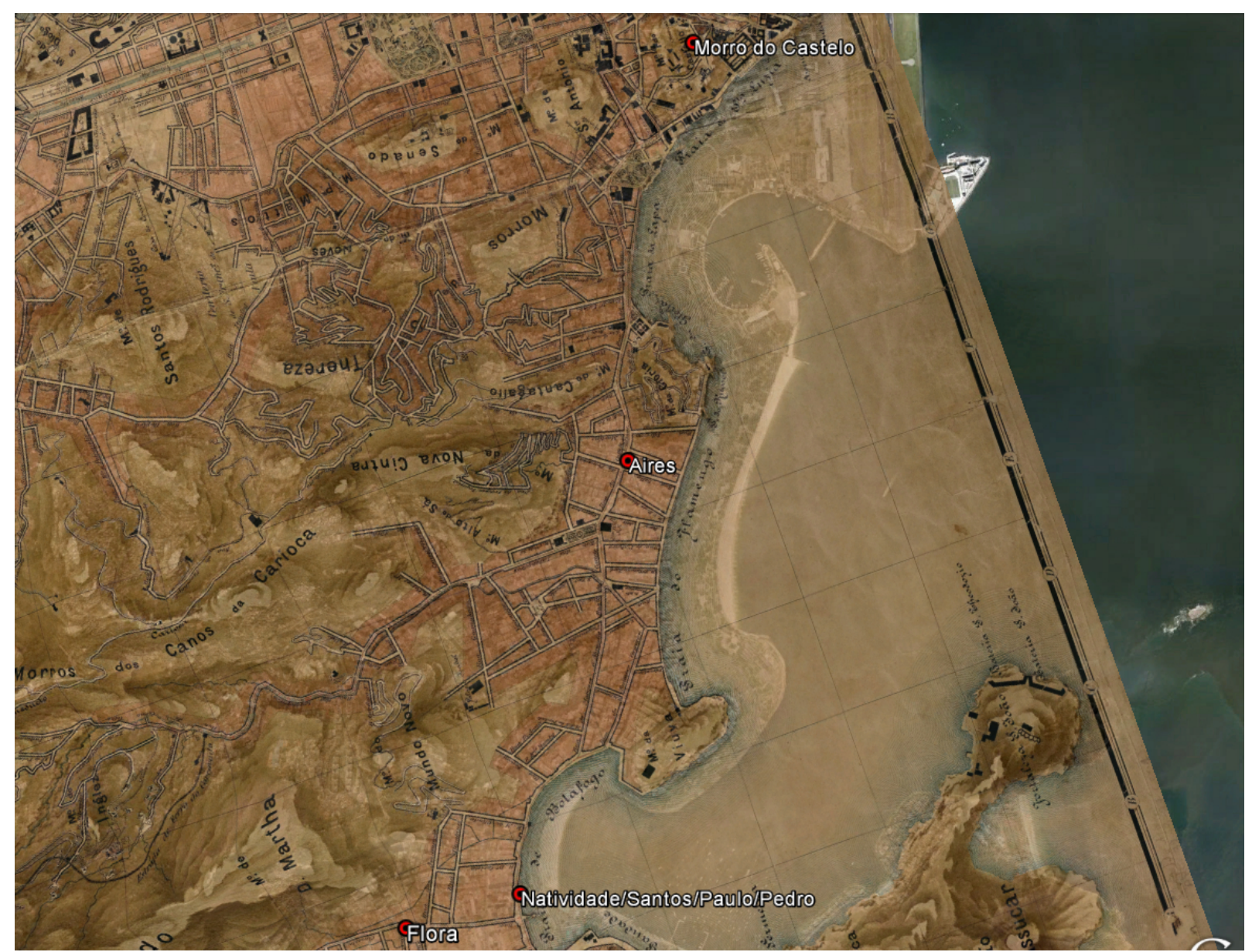

Figura 5 (com mapa Laemmert do Rio de Janeiro (c. 1885) sobre imagem de satélite). ${ }^{52}$

Essa conversão da história e da topografia da cidade em forças ativas da narração de Machado, consumada no limiar do século XX, pode ser visualizada em processo na sucessão de seus livros anteriores.

Nos quatro romances da chamada "fase romântica", a composição do espaço urbano é notavelmente sumária. Raros topônimos do Rio de Janeiro são mencionados. No nível cronotópico, verifica-se escassa movimentação de personagens. Estes não passeiam, não matutam ambulando, não observam o correr da paisagem a cavalo ou de carruagem como nos livros da maturidade. Quase não há cenas a céu aberto, a não ser nas varandas e chácaras (quintais) das residências dos personagens. Os campos de visão são fortemente limitados em relação ao espaço total. Poucas exceções a essa verdadeira agorafobia são mencionáveis: o encontro de Jorge com Iaiá ao longo do Aqueduto de Santa Teresa, em Iaiá Garcia (cap. XII); a espera ansiosa de Estêvão pela saída da amada Guiomar à porta do Teatro Ginásio, em $A$ mão e a luva (cap. VI); ou as cavalgadas de Helena na estrada do Andaraí, no título homônimo. $\mathrm{O}$ espaço reconstruído é sobretudo o da trama das relações sociais no interior das salas de visita, salões de baile e alcovas (castas) de famílias da elite branca, em torno das quais gira uma roda de intrigas de casamento e herança. ${ }^{53}$ A rigidez pachorrenta das posições topográficas, entre as quais os deslocamentos não são quase nunca narrados, é um efeito daninho da cenografia da enunciação, na qual a escravidão é tratada como um dado da natureza, a ponto de a massa de 
cativos negros quase nunca ser audível ou visível e a mobilidade entre as classes praticamente inexistir. Helena e Iaiá Garcia começam timidamente a se espraiar pela cidade e pelo mundo. Mas, como em Ressurreição e $A$ mão e a luva, a exiguidade dos campos de visão e a obscuridade quase completa do espaço total não deixam de restringir a margem de manobra de reflexão e digressão do narrador sobre sua própria produtividade.

É somente em 1880-1 que, repentinamente aflorada nesse acanhado teatro de província, a pulsação da cidade inicia seu desfile triunfal através do romance machadiano. "Levanta-te e entra na cidade": 54 o oráculo bíblico incorporado por Brás Cubas ao abandonar seu idílio rural na Tijuca se torna o motto geográfico de Machado nos grandes livros da maturidade.

Para demonstrá-lo num golpe de vista, basta comparar a magreza toponímica da topografia de Ressureição e $A$ mão e a luva, por exemplo, com a copiosidade de ruas, praças, bairros e instituições cariocas mencionadas em quaisquer dos livros pós-1880, inclusive o curto Memorial de Aires. Os romances "românticos" de Machado são narrados por uma voz estática e pouco aventurosa, agenciada por antolhos de decoro que tornam os campos de visão incapazes de atravessar as paredes e fachadas dos casarões senhoriais, cujos cômodos se apresentam como pequenos palcos italianos. Mas, depois que Machado passa à primeira pessoa ambulante de Brás Cubas e encontra a voz de seus grandes livros, o espaço textual se diversifica dramaticamente com a amplificação e a densificação da topografia e a aceleração das cronotopias da narração, cada vez mais orientada pelas instituições sociais (teatros, salões, bailes, igrejas), políticas (secretarias, ministérios, palácios, tribunais) e econômicas (estabelecimentos comerciais, a Bolsa, bancos) da cidade. Esses lugares funcionam como matrizes de sociabilidade interligadas pelas ruas apinhadas da capital litorânea do país e conectadas em variados graus aos fluxos velozes da continentalização e da mundialização. No Machado pós-1880, lugares distantes do resto do Brasil e do mundo passam a aparecer frequentemente no espaço total, com destaque para diversos países e cidades da Europa, da América e da Ásia, além das províncias e cidades mais importantes do Império.

Como afirma Harvey sobre o ambiente cultural daquele fin-de-siècle, já não era mais possível "evitar a questão do internacionalismo, da sincronia, da temporalidade insegura e da tensão, no âmbito da medida dominante de valor, entre o sistema financeiro e sua base monetária ou tangível". ${ }^{55}$ Machado, nesse sentido, desperta de seu sono histórico no berço esplêndido dos primeiros romances e, completamente armado como Minerva, ocupa a cidade do Rio de Janeiro nos livros pós-1880 em sucessivas manobras textuais de contenção do "tempo explosivo" da circulação acelerada de mercadorias e suas moedas falsas literárias através da cidade. $\mathrm{O}$ romance machadiano, em primeira ou terceira pessoa, alternando entre estratégias de posição (Dom Casmurro) e movimento (Quincas Borba), passa a mapear e promover sua própria continentalização da metrópole nascente para arrebatá-la aos esquemas banais da ficção urbana da época e, por tabela, ao poder destrutivo do Estado-nação liberal e da finança. A coincidência cronológica entre a publicação de Esaú e Jacó e o início da demolição do morro do Castelo (e, por sinédoque, do Rio antigo) fornece um testemunho eloquente da importância atribuída por Machado à conquista literária do espaço urbano diante da usurpação de seus lugares identitários pelo rentismo financeiro e beletrístico. A velha cantiga sertaneja do pai da pitonisa Bárbara, irrompida no topo do morro do Castelo, manda um recado sutil de que se trata, em certo sentido, do mesmo movimento de contra-ataque da 
voz certeira de Riobaldo Tatarana contra a conversa miúda da narrativa regionalista dominante em 1956, lastro estético da desfiguração dos lugares e falares do Sertão pela uniformização da cidade. Tendo dominado com virtuosidade a estratégia tradicional da "guerra de posições" consagrada pela narrativa realista, esses dois romancistas-chave do século XX se armam para uma "guerra de movimentos" mais propícia à operação ficcional em territórios amplamente dominados pelo inimigo hegemônico.

No centro de tais operações está o mapa, essa ponte móvel entre as silenciosas visões aéreas do território e o vozerio chão das veredas do sertão e da cidade.

Não é factível nem recomendável, pelas específicas condições de historicidade de cada livro, traçar um esquema tipológico do espaço do romance brasileiro do século XX na exiguidade de um artigo. Cada romance é em si um autêntico atlas de estratégia espaçotemporal. No entanto, procurei assinalar como funcionaram os regimes de interferência de alguns campos de força da literatura em sua tentativa de repontuar os ritmos administrados da reprodução do espaço literário de repetição no contexto geográfico do embate territorial sertão x cidade. E, funcionando essas interferências na diacronia da história literária, como a questão da historicidade do espaço, encenada pelo arranjo posicional das vozes e pontos de vista da narração, assume papel fulcral.

Para determinar os modos cambiantes das espacializações narrativas, é necessário focalizar as velocidades relativas de seus objetos e ações para além das posições numa sincronia de complexos espaciais. Vigente nos três níveis do espaço reconstruído formulados por Gabriel Zoran, a operação da espiral do espaço-tempo da narrativa parte da relação espaço/tempo que governa a dinâmica geográfica do texto. Espaço no tempo = velocidade; velocidade no tempo $=$ aceleração. Somente nos termos relacionais da cena enunciativa haverá condições de analisar in vivo os regimes de interação espaçotemporal entre o romance e o palavreado dominante do mundo. Se o macroato de fala do romance de invenção necessita ser analisado em sua organicidade geoespacial, é preciso avaliar as turbulências que seus brados e murmúrios provocam no escoamento manjado da reprodução de mercadorias, sobretudo as literárias.

\section{Agradecimentos}

À Capes e à Comissão de Pós-Graduação do Departamento de Teoria Literária e Literatura Comparada (DTLLC / FFLCH-USP), pelo financiamento concedido.

A Roberto Zular e aos colegas do grupo de estudos, pelas discussões e sugestões de bibliografia.

\section{Notas de fim}

\footnotetext{
${ }^{1}$ Ariano Suassuna, A pedra do reino, Rio de Janeiro, José Olympio, 1971, p. 457.

${ }^{2}$ Oswald de Andrade, Serafim Ponte Grande, São Paulo, Globo, 2007, p. 99.

${ }^{3}$ Franco Moretti, Atlas literário do romance europeu, São Paulo, Boitempo Editorial, 2003, p. 13.
} 
${ }^{4}$ João Guimarães Rosa, Grande sertão: veredas, Rio de Janeiro, José Olympio, 1965, p. 129.

${ }^{5}$ Frei Vicente do Salvador, História do Brasil 1500-1627, Rio de Janeiro, Melhoramentos, 1965, p. 61.

${ }^{6}$ Ver Evaldo Cabral de Mello, "Prefácio" in A educação pela guerra, São Paulo, Companhia das Letras, 2014.

${ }^{7}$ Ver Max Justo Guedes, A cartografia impressa do Brasil 1566-1922, Rio de Janeiro, Capivara, 2012.

${ }^{8}$ Para os conceitos de "continente" e "ilha" na história da ocupação do território nacional, ver Gilberto Freyre,

Continente e ilha, Rio de Janeiro, Casa do Estudante do Brasil, 1943.

${ }^{9}$ Freyre, Continente e ilha, op. cit., p. 17-8.

${ }^{10}$ Para os conceitos de "espaço do capital" "tempo explosivo" e "destruição criativa", ver David Harvey, Spaces of Capital, Londres, Routledge, 1989. A "aniquilação do tempo pelo espaco" é a fórmula marxista extraída dos Grundrisse que Harvey emprega como ponto de partida de sua teoria geográfica.

${ }^{11}$ Fernando Sabino, O encontro marcado, Rio de Janeiro, Record, 1976, p. 81.

12 Ver Willi Bolle, grandesertão.br, São Paulo, Duas Cidades, Editora 34, 2004.

${ }^{13}$ Ver Boris Tomachevski, "Thématique" in Tzvetan Todorov (org.), Théorie de la littérature, Paris, Éditions du Seuil, 1965 .

${ }^{14}$ Ver Milton Santos, A natureza do espaço, São Paulo, Edusp, 2008.

${ }^{15}$ Ver Dominique Maingueneau, O contexto da obra literária, São Paulo, Martins Fontes, 2001.

${ }^{16}$ Santos, A natureza do espaço, op. cit., p. 82.

${ }^{17}$ Bertrand Westphal, "Pour une approche géocritique des textes" in La Géocritique, mode d'emploi, Limoges, PULIM, 2000, p. 21 .

${ }^{18}$ Maingueneau, $O$ contexto da obra literária, op. cit., p. X.

${ }^{19}$ Ver Gabriel Zoran, "Towards a Theory of Space in Narrative", Poetics Today, vol. 5, no. 2, 1984, p. 309-35.

${ }^{20}$ Para os conceitos de "horizonte de expectativa" e "campo de experiência", ver Reinhardt Koselleck, Futuro passado, Rio de Janeiro, Contraponto/Editora PUC-Rio, 2006.

${ }^{21}$ Zoran, “Towards a Theory...”, op. cit., 1984.

${ }^{22}$ Idem, p. 315.

${ }^{23}$ Idem, ibidem.

${ }^{24}$ Idem, p. 324.

${ }^{25}$ Idem, p. 332.

${ }^{26}$ Idem, ibidem.

${ }^{27}$ Para o funcionamento da indeterminação entre Deus e Diabo na forma do romance, ver João Adolfo Hansen, $o$ $O$, São Paulo, Hedra, 2004.

${ }^{28}$ Ver Guedes, A cartografia histórica do Brasil, op. cit. Sobre o imaginário republicano do espaço-nação, ver José Murilo de Carvalho, A formação das almas: o imaginário da república no Brasil, São Paulo, Companhia das Letras, 2011.

${ }^{29}$ David Harvey, A condição pós-moderna, São Paulo, Edições Loyola, 2005, p. 248.

${ }^{30}$ Gilles Deleuze, Lógica do sentido, São Paulo, Perspectiva, 2003, p. 193.

${ }^{31}$ Eugenne Lunn, Marxism and Modernism, 1985, apud Harvey, A condição pós-moderna, op. cit., p. 30.

${ }^{32}$ Mário de Andrade, "Ode ao burguês" in Poesias completas, Belo Horizonte, Villa Rica, 1993, p. 88.

${ }^{33}$ Andrade, Serafim Ponte Grande, op. cit., p. 57.

${ }^{34}$ Graciliano Ramos, São Bernardo, Rio de Janeiro, Record, 1988.

${ }^{35}$ Suassuna, A pedra do reino, op cit., p. 6.

${ }^{36}$ Idem, ibidem.

${ }^{37}$ Espera-se que o recente falecimento de Suassuna, ocorrido quando este artigo era finalizado, estimule o letárgico mercado editorial brasileiro a preparar uma reedicão decente de A pedra do reino. Pode ser até mesmo que a morte do escritor contribua para a inclusão da saga de Pedro. Quaderna no cânone dos romances do século XX. Mas quem ainda se disporá a enfrentar suas centenas de páginas neste $2014 \mathrm{em}$ que as palavras de ordem mais eficazes não precisam passar de 140 caracteres?

38 Walter Benjamin, "Infância em Berlim por volta de 1900" in Obras escolhidas, vol. 2, São Paulo, Brasiliense, 1996, p. 73.

39 Ver Alan Viggiano, Itinerário de Riobaldo Tatarana, Belo Horizonte, Comunicação/ Brasília, INL, 1974; e Bolle,

grandesertão.br, op. cit., 2004.

${ }^{40}$ Para a intertextualidade cenográfica com Grande sertão: veredas, ver Érico Melo, Rumo a rumo de lá: atlas fotográfico de Corpo de baile, tese (doutorado em literatura brasileira), FFLCH-USP, São Paulo, 2011, cap. 4.

${ }^{41}$ Os traços retorcidos, desenhados com base no rastreamento de Grande sertão: veredas realizado por Willi Bolle, designam os caminhos da travessia de Riobaldo, concatenados na sequência branco-rosa-vermelho, que indica a sucessão dos eventos da narrativa - isto é, do nascimento de Riobaldo até seu encontro com Nhorinhá, na Aroeirinha; da primeira tentativa de travessia do Liso do Sussuarão até a batalha da fazenda São Serafim; e da São Serafím ate o presente da enunciação, passando pela chefia do Urutu Branco até seu final trágico na batalha do Paredão. O total de tais andanças chega a mais de 9 mil $\mathrm{km}$. O marco "Riobaldo" indica a situaçao do provável cenário da fazenda do ex-jagunço convertido por herança em grande proprietário, onde se narra o romance. Para os "mapas da jagunçagem", ver Bolle, grandesertão.br, op. cit. 
42 A linha reta inclinada entre as fazendas do Mutúm ("Campo Geral") e Saturnino ("O recado do morro"), denominada loxodrômica em jargão cartográfico, é a espinha dorsal do território das sete novelas de Corpo de baile, pois determina o rumo geodésico resultante do S vermelho da estrada da comitiva de "O recado do morro", conto central da Parábase do Tivro. Para o mapeamento detalhado de Corpo de baile, ver Melo, Rumo a rumo dé lá, op. cit, cap. 1-2.

${ }^{43}$ Para o embate heideggeriano entre Ser e Vir-a-Ser na modernidade, ver Harvey, A condição pós-moderna, op. cit., p. 256.

${ }^{44}$ Para a cronologia do "projeto de escrita" dos livros de 1956, ver Ana Luiza Martins Costa, "Via e viagens: a elaboração de Corpo de baile e Grande Sertão: Veredas" in Cadernos de literatura brasileira nos. 20-21, São Paulo,

Instituto Moreira Salles, 2006.

45 Mladen Dolar, $A$ voice and nothing more, Cambridge, MIT Press, 2006.

${ }^{46}$ Rosa, Grande sertão: veredas, op. cit., p. 22.

${ }^{47}$ Para uma boa discussão sobre a polêmica entre as doutrinas da "guerra de posições" (consagrada pelo triunfo aliado nas trincheiras da Primeira Guerra Mundial) e da "guerra de movimentos" (o modo de operação por excelência das guerrilhas e tropas irregulares) no pensamento militar brasileiro da primeira metade do século XX, ver Daniel Aarăo Reis, Luís Carlos Prestes, um revolucionário entre dois mundos, São Paulo, Companhia das Letras, 2014, cap. 3.

48 Para uma interessante tipologia do campo da batalha na literatura de ficção, ver Catherine Milkovitch-Rioux, "Le Champ de bataille, ou les métamorphoses de l'espace" in Westphal, La Géocritique mode d'emploi, op. cit., pp. 59-73.

${ }^{49}$ Apud Cardeman, O Rio de Janeiro nas alturas, op. cit., p. 37.

${ }^{50}$ Carlo Giulio Argan, "Urbanismo, espaço e ambiente" in História da arte como história da cidade, São Paulo, Martins Fontes, 2005, p. 214.

${ }^{51}$ Érico Melo, "Por uma geografia do romance brasileiro do século XX: esboço de roteiro". Veredas - Revista da Associação Internacional de Lusitanistas, no. 21, 2014.

$52 \mathrm{O}$ mapa parte do pressuposto de que a mansão de Santos e Natividade se situa no final da praia (próximo à Urca), como se pode inferir do episódio em que o banqueiro vislumbra sua casa ao longe desde o início da enseada, ao voltar de carruagem do Centro (cap. VI). Aires foi, por convenção, posicionado no ponto médio da rua do Catete, assim como Flora na rua de São Ċlemente. De qualquer modo, pequenas variações nessas coordenadas

não alterariam o quadro geral da topografia do livro.

${ }^{53}$ Ver Roberto Schwarz, Ao vencedor, as batatas, São Paulo, Duas Cidades, 2000.

${ }^{54}$ Machado de Assis, Memórias póstumas de Brás Cubas in Obra completa, op. cit., p. 129.

${ }^{55}$ Harvey, A condição pós-moderna, op. cit., p. 239. 